\title{
EKSTRAKSI KARAGINAN RUMPUT LAUT MERAH (Kappaphycus alvarezii) DENGAN PERLAKUAN PERENDAMAN DALAM LARUTAN BASA
}

\author{
Jessica E. Panggabean ${ }^{1}$, Verly Dotulong ${ }^{2}$, Roike Iwan Montolalu ${ }^{2}$, \\ Lena Damongilala ${ }^{2}$, Silvana D. Harikedua ${ }^{2}$, Daisy M. Makapedua ${ }^{2}$
}

\author{
${ }^{1)}$ Mahasiswa pada Program Studi Teknologi Hasil Perikanan FPIK Unsrat Manado. 95115. \\ ${ }^{2}$ Staf pengajar pada Program Studi Teknologi Hasil Perikanan FPIK Unsrat Manado. 95115.
}

\begin{abstract}
Semi-refined carrageenan are a type of carrageeanan product that have a low level of purity because it still contains a small amount of cellulose within the carageenan. The purpose of this study is to find out the effect of the concentration of both $\mathrm{NaOH}$ and $\mathrm{KOH}$ towards rendemen, and the physical and chemical characteristic of semi refined carrageenan made from Kappaphycus alvarezii seaweed, and also to minimize the use of chemical product on SRC production process. The method used in this study is steaming method. The results are the rendemen from $\mathrm{NaOH}$ is $10 \%$ and $\mathrm{KOH} 14 \%$. This proves that the concentration of alkali affects the amount of rendemen. The higher the amount of alkali used, the higher the amount of rendemen obtained. Water content obtained from the $\mathrm{NaOH}$ samples are 3,75\%; while those from the $\mathrm{KOH}$ samples are $5 \%$. The ash content of semi-refined carrageenan obtain from $\mathrm{NaOH}$ samples are $55,42 \%$ and $\mathrm{KOH}$ are $55,27 \%$. For the $\mathrm{pH}$ level on semi-refined carrageenan obtain from the $\mathrm{NaOH}$ samples are 8,06; and $\mathrm{KOH}$ are 8,69. The alkali concentration greatly affects the amount of rendemen that is obtained because a higher concentration of alkali during the alkalization process will result in higher $\mathrm{pH}$ level, therefore the extration ability of alkali are increased.
\end{abstract}

Keyword: Seaweed, Kappaphycusalvarezii, Semi-refined carrageenan.

Semi refined carrageenan (SRC) merupakan salah satu produk karaginan dengan tingkat kemurnian yang rendah karena masih mengandung sejumlah kecil selulosa yang ikut mengendap bersama karaginan. Penelitian ini bertujuan untuk mengetahui pengaruh konsentrasi $\mathrm{NaOH}$ dan konsentrasi $\mathrm{KOH}$ terhadap rendemen, sifat fisik, dan sifat kimia pada pembuatan Semi Refined Carageenan dari rumput laut Kappaphycus alvarezii serta meminimalisir penggunaan bahan kimia pada pembuatan Semi Refined Carageenan. Metode yang digunakan pada penelitian ini adalah metode uap. Hasil penelitian yang diperoleh seperti rendemen dengan perendaman $\mathrm{NaOH}$ adalah $10 \%, \mathrm{KOH} 14 \%$. Hal ini membuktikan bahwa konsentrasi alkali mempengaruhi jumlah rendemen. Semakin tinggi jumlah alkali, semakin tinggi rendemen yang didapatkan. Kadar air yang diperoleh adalah kadar air pada sampel dengan $\mathrm{NaOH}$ yaitu $3,75 \%$; sedangkan untuk kadar air sampel $\mathrm{KOH}$ yaitu 5\%. Hasil kadar abu Semi Refined Carrageenan (SRC) untuk sampel dengan $\mathrm{NaOH}$ yaitu 55,42\%; sedangkan untuk sampel $\mathrm{KOH}$ yaitu 55,27\%. Untuk nilai pH Semi Refined Carrageenan (SRC) pada sampel dengan $\mathrm{NaOH} \mathrm{8,06;} \mathrm{sampel} \mathrm{dengan} \mathrm{KOH} 8,69$. Konsentrasi alkali sangat mempengaruhi rendemen yang dihasilkan karena semakin tinggi konsentrasi alkali selama proses alkalisasi berlangsung, menyebabkan pHnya semakin tinggi sehingga kemampuan alkali dalam mengekstrak semakin besar.

Kata kunci: Rumputlaut, Kappaphycusalvarezii, Semi Refined Carrageenan.

\section{PENDAHULUAN}

Indonesia merupakan negara yang kaya akan sumber daya alamnya terlebih hasil lautnya. Salah satu hasil laut yang saat ini telah banyak ditemukan adalah rumput laut. Rumput laut atau algae juga dikenal dengan nama seaweed yang merupakan bagian terbesar dari tanaman laut. Peningkatan permintaan pasar dunia terhadap jenis rumput laut Kappaphycus alvarezii memacu perkembangan budidaya. Diketahui bahwa negara Filipina merupakan negara pertama yang dapat meningkatkan produksi Kappaphycus alvarezii melalui budidaya (Poke dkk, 2014). Untuk produksi rumput laut di Sulawesi Utara mengalami penurunan drastis sejak akhir tahun 2000, hal tersebut disebabkan menurunnya produksi rumput laut di Minahasa Utara, khususnya di Pulau Nain yang merupakan sentra produksi rumput laut di Sulawesi Utara (Mudeng dkk, 2014). Puncak produksi di Pulau Nain terjadi tahun 1966-2000 sebanyak 350-400 ton per bulan, kemudian menurun pada akhir tahun 2000 dan mencapai titik nol produksi pada awal 
tahun 2003 (Gerung et al. 2008).Rumput laut jenis Kappaphycus alvarezii yang didapatkan dari Pulau Nain, Sulawesi Utara mempunyai kekuatan gel yang memiliki tingkat elastisitas tinggi (Montalalu et al, 2007).

Saat ini, rumput laut telah banyak digunakan dalam aplikasi pangan maupun non pangan yang telah mengalami proses pengekstrasian. Beberapa jenis rumput laut yang sering digunakan antara lain; Rumput laut merah (Euchema cottonii), (Euchema spinosum) dan rumput laut cokelat (Sargassum polycystum).

Rumput laut dapat dikonsumsi dengan dilakukannya pengolahan. Pengolahan rumput laut dapat bermacam-macam sesuai dengan hasil produk apa yang akan dicapai. Sebagian besar masyarakat khususnya di Indonesia hanya mengetahui pembudidayaan mengenai rumput laut saja, namun tidak mengetahui peluang yang ada di dalam rumput laut. Tetapi ada juga masyarakat yang sudah tau mengenai peluang ataupun manfaatnya, namun tidak mengetahui cara pengolahan yang baik dan benar sehingga rumput laut hanya diekspor dalam bentuk kering, yang dimana menyebabkan rumput laut mengalami penurunan untuk nilai tambahnya.

Rumput laut bermanfaat sebagai antioksidan, anti peradangan, anti diabetes, dan anti kanker (Sanger et al., 2018). Rumput laut perlu diolah menjadi produk setengah jadi seperti agar, alginat, dan karaginan untuk meningkatkan nilai tambahnya. Alginat dan agar-agar merupakan senyawa karbohidrat yang terdapat dinding sel rumput laut, namun yang membedakan keduanya adalah pada komponen penyusun.

Perlu diketahui bahwa kebutuhan dunia terhadap karaginan terus mengalami peningkatan dengan bertambahnya penduduk di dunia terutama di Indonesia. Karena itu, sangat diperlukan adanya upaya serius untuk memacu produktivitas Kappaphycus alvareziis sebagai sumber karaginan, baik secara kualitas maupun kuantitas. Ekstraksi rumput laut menghasilkan dua jenis karaginan yaitu semi refine carrageenan (SRC) dan refine carrageenan (karaginan murni). Karaginan semi murni merupakan karaginan yang memiliki tingkat kemurnian rendah, karena masih mengandung sejumlah kecil selulosa yang ikut mengendap bersama karaginan (Rizal, 2016), sedangkan karaginan murni merupakan karaginan yang sudah bebas dari selulosa melalui proses pengendapan (Ega, 2016). Karaginan berfungsi sebagai stabilisator (pengatur keseimbangan), bahan pengental dan pembentuk gel dalam bidang industri pengolahan makanan. Karaginan juga berfungsi sebagai bahan pengemas seperti bahan pembuatan edible coating dan edible film. Edible film dari karaginan memiliki sifat barrier yang baik terhadap gas, namun, memiliki permeabilitas uap air yang tinggi dikarenakan sifatnya yang hidrofilik, yang membatasi penggunaannya dalam pengemasan makanan (Alves et al. 2011 dalam Togas, 2017).

Karaginan semi murni sering dimanfaatkan pada industri non pangan sebagai bahan gelasi pada makanan hewan dalam kaleng, air freshner, shampo, sabun mandi, dan pelapis gigi (Saputra, 2012).

Karaginan semi murni dapat diperoleh dengan dilakukannya proses ekstraksi. Proses ekstraksi rumput laut menjadi karaginan dipengaruhi oleh beberapa faktor yaitu konsentrasi alkali, suhu ekstraksi, waktu ekstraksi, jenis rumput laut, dan pengendapan. Konsentrasi alkali yang tinggi dapat menghasilkan rendemen yang tinggi. Menurut Nasruddin dkk. (2016) penambahan larutan alkali $(\mathrm{NaOH})$ menyebabkan kemampuan mengekstrak semakin tinggi. Hal ini dapat membantu ekstraksi polisakarida menjadi sempurna dan mempercepat terbentuknya 3,6anhidro galaktosa selama proses ekstraksi berlangsung, sehingga rendemen meningkatkan.

Minimnya produksi karaginan dalam negeri yang tidak sejalan dengan kebutuhan karaginan yang semakin meningkat setiap tahunnya untuk mencukupi kebutuhan dalam negeri serta banyaknya konsentrasi bahan kimia pada pembuatan karaginan di kalangan masyarakat mendorong dilakukannya rencana penelitian ini, selain itu karena karaginan termasuk produk olahan rumput laut yang bernilai ekonomi tinggi. Penelitian ini diharapkan pula dapat memberikan peluang bagi masyarakat untuk mengembangkan rumput laut menjadi karaginan yang bernilai ekonomi tinggi dengan cara yang sederhana tetapi memiliki kualitas yang baik. Cara sederhana yang dilakukan di penelitian ini adalah mengekstraksi Kappaphycus alvarezii menjadi karaginan dengan menggunakan metode uap dan pada akhirnya diharapkan dapat dikembangkan untuk memenuhi kebutuhan dalam negeri yang sebagian masih di impor dan 
dapat memberi nilai tambah pada rumput laut yang merupakan sumber pembuatan karaginan dengan meminimalisir penggunaan bahan kimia.

\section{METODE PENELITIAN}

\section{Alat dan Bahan} karagenan:

Alat yang digunakan dalam pembuatan

Kompor, wadah dengan muatan $\pm 10 \mathrm{~L}$, timbangan digital 4 digit, gelas ukur $100 \mathrm{~mL}$, spatula, kertas lakmus, kain saring (blacu), Beaker glass $1000 \mathrm{~mL}$, gunting, kuali besar (belanga), saringan, aluminuim foil.

\section{Bahan yang digunakan:}

Rumput laut jenis Kappaphycus alvarezii diperoleh dari Pulau Nain, Sulawesi Utara. Bahan penunjang penelitian yaitu $\mathrm{NaOH}$, $\mathrm{KOH}$, dan $\mathrm{KCL}$ serta aquades

\section{HASIL DAN PEMBAHASAN}

\section{Rendemen Semi Refined Carrageenan}

Rendemen merupakan berat (bobot) karaginan dari rumput laut. Berdasarkan penelitian yang telah dilakukan rendemen yang diperoleh pada perlakuan konsentrasi $\mathrm{NaOH} 3 \%$ (sampel A) yaitu $10 \%$, juga hasil rendemen pada perlakuan konsentrasi $\mathrm{KOH} 4 \%$ (sampel B) yaitu $14 \%$ dengan waktu ekstraksi 5 jam.

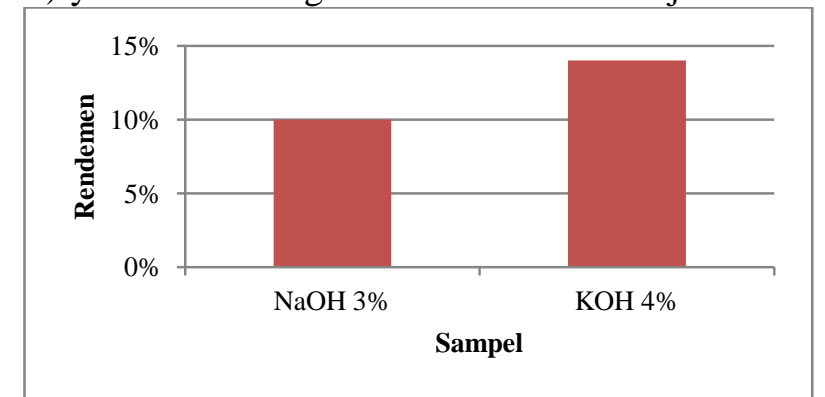

Gambar 1. Rendemen Semi Refined Carrageenan (SRC).

Diketahui rendemen yang dihasilkan oleh Bunga, dkk. (2013) adalah $19,377-28,402 \%$ dari rumput laut yang didapat berdasarkan umur panen yang berbeda-beda yakni pada perlakuan $0-20$ hari rendemen karaginan mengalami peningkatan, sedangkan pada perlakuan 30-50 hari rendemen mengalami penurunan. Jadi, umur panen dari rumput laut juga mempengaruhi hasil rendemen karaginan yang diperoleh.
Rendahnya rendemen yang dihasilkan ini kemungkinan juga dipengaruhi oleh waktu ekstraksi dan konsentrasi basa. Menurut Dalimunthe (2015), dinyatakan bahwa semakin tinggi suhu penyulingan, maka air yang hilang semakin banyak, sehingga kadar air semakin merendah. Pada penelitian ini untuk ekstraksi menggunakan metode uap dan teknik pengeringan, menggunakan metode oven.

Sebagaimana dikemukakan oleh Hidayat (2004) bahwa semakin rendah kadar air dalam rumput laut maka semakin baik kualitas rumput laut tersebut. Jadi, produk SRC ini telah memenuhi standar dengan hasil $3,75 \%$ dan $5 \%$ untuk tepung karaginan.

\section{Kadar air}

Berdasarkan histogram kadar air Semi Refined Carragenan (SRC), dapat dilihat bahwa kadar air pada sampel A yaitu 3,75\%; sedangkan untuk kadar air sampel B yaitu $5 \%$.

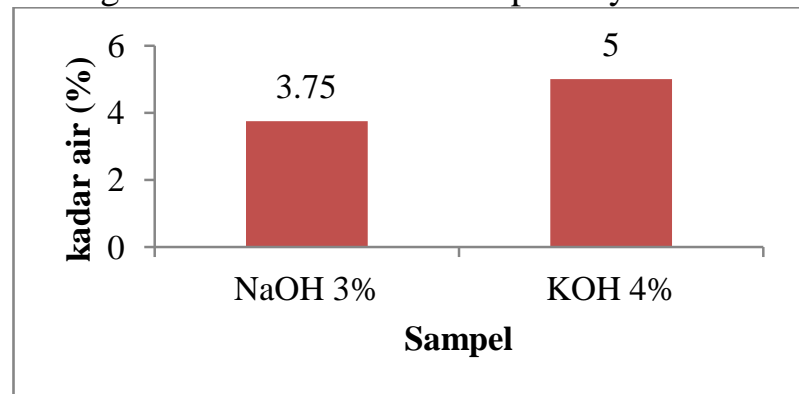

Gambar 2. Histogram kadar air Semi Refined Carrageenan (SRC)

Dari hasil ini dapat dilihat bahwa ekstraksi rumput laut kering yang direndam dalam larutan $\mathrm{KOH}$ konsentrasi $4 \%$ memiliki kadar air yang lebih tinggi daripada hasil ekstraksi rumput laut kering yang direndam dalam larutan $\mathrm{NaOH} 3 \%$.

Hasil penelitian yang dilakukan oleh Erjanan (2017) menghasilkan kadar air tertinggi

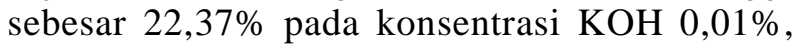
sedangkan pada konsentrasi $\mathrm{KOH} 0,15 \%$ menghasilkan kadar air sebesar $17,75 \%$. Hal ini menunjukkan bahwa konsentrasi $\mathrm{KOH}$ berpengaruh terhadap kadar air yang diperoleh. Terlihat bahwa semakin tinggi konsentrasi $\mathrm{KOH}$ maka semakin rendah kadar air karaginan, hal ini diduga disebabkan oleh kemampuan $\mathrm{KOH}$ dalam mengekstrak dan menghambat terjadinya peningkatan air dalam molekul rumput laut Eucheuma Cottonii sehingga kadar air menjadi berkurang. Sebagaimana penelitian yang dilakukan Anwar et al. (2013) bahwa penurunan kadar air alginat diakibatkan adanya 
suasana basa dari larutan $\mathrm{KOH}$ yang mampu menghambat terjadinya suatu peningkatan air dalam molekul alginat, dengan meningkatnya konsentrasi $\mathrm{KOH}$ yang digunakan maka dapat mengurangi garam-garam mineral yang terkandung di dalamnya. Kadar air karaginan yang dihasilkan dapat dipengaruhi oleh beberapa faktor, diantaranya adalah jenis dan umur rumput laut yang digunakan serta teknik ekstraksi yang dipakai dalam pembuatan karaginan. Selain itu, teknik pengeringan yang digunakan menjadi faktor penting yang mempengaruhi kadar air karaginan yang dihasilkan. Pada penelitian ini, teknik ekstraksi sendiri menggunakan metode uap.

Diketahui bahwa kadar air dengan standar FAO tepung karaginan yaitu maksimal $12 \%$. Sedangkan, kadar air untuk produk SRC yang dihasilkan pada penelitian yang dilakukan Erjanan (2017) dan Tamaheang (2017) lebih tinggi dari $12 \%$. Sedangkan pada penelitian ini dihasilkan kadar air yang lebih rendah dari hasil Erjanan (2015). Sebagaimana dikemukakan oleh Hidayat (2004) bahwa semakin rendah kadar air dalam rumput laut maka semakin baik kualitas rumput laut tersebut. Jadi, produk SRC ini telah memenuhi standar dengan hasil 3,75\% dan 5\% untuk tepung karaginan.

\section{Kadar Abu}

Berdasarkan histogram nilai kadar abu Semi Refined Carrageenan (SRC) dapat dilihat bahwa nilai kadar abu untuk sampel A yaitu $55,42 \%$; sedangkan untuk sampel B yaitu $55,27 \%$.

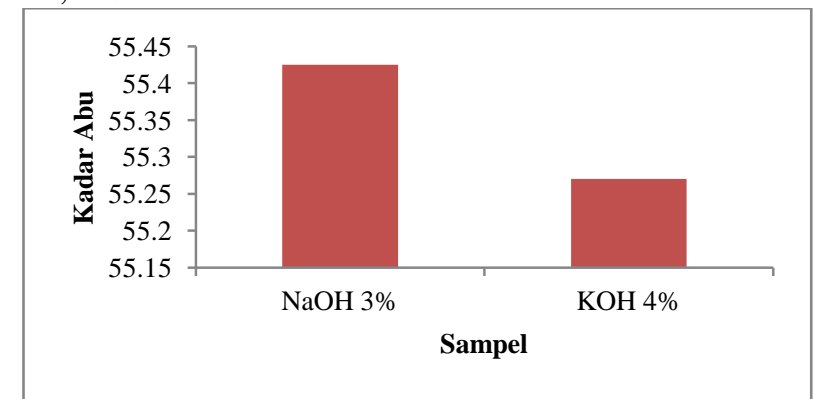

Gambar 3. Kadar abu Semi Refined Carrageenan (SRC).

Penelitian yang dilakukan Erjanan (2017) didapatkan hasil tertinggi 34,50\% dalam pengekstrasian menggunakan $\mathrm{KOH}$ sebanyak $0,05 \%$. Sedangkan penelitian yang dilakukan oleh Prasetyowati (2008) didapatkan nilai kadar abu yakni $35 \%$ dalam pengeksrasian menggunakan $\mathrm{NaOH}$ sebanyak $5 \%$. Kadar abu yang dihasilkan lebih tinggi kemungkinan karena kadar mineral yang cukup tinggi pada air keran sehingga menyebabkan hasil kadar abu menjadi lebih tinggi dibandingkan dengan hasil kadar abu Erjanan (2017). Namun pada penelitian ini, rumput laut yang sudah menjadi filtrat setelah penambahan KCL, dicuci kembali sebanyak tiga kali. Untuk pencucian terakhir menggunakan akuades. Sedangkan penelitian yang dilakukan Erjanan (2017), tidak dilakukan pencucian setelah terbentuknya filtrat karaginan, sehingga kemungkinan karaginan yang dihasilkan belum benar-benar murni.

Diketahui bahwa kadar abu yang terbentuk berasal dari garam dan mineral yang terbentuk pada rumput laut yaitu $\mathrm{Na}$ yang terkandung pada $\mathrm{NaOH}$ (Desiana, 2015). Selain itu, menurut Winarno (1997), tingginya kadar abu karaginan dipengaruhi oleh adanya garam dan mineral lain yang menempel pada rumput laut seperti natrium, kalsium dan literum. Masthora (2016) menyatakan bahwa semakin tua umur panen rumput laut maka kadar abu yang dihasilkan juga semakin meningkat karena semakin lama rumput laut berada dalam suatu perairan, maka semakin banyak kandungan garam-garam mineral yang diserap oleh rumput laut yang dapat menyebabkan kadar abu karaginan juga meningkat.

Untuk standar FAO tidak memenuhi karena hasil yang diperoleh berupa Semi Refined Carrageenan sedangkan untuk standar FAO adalah terpung karaginan sehingga hasil kadar abu Semi Refined Carrageenan tersebut cukup baik untuk kemudian dijadikan tepung karena akan melewati proses pemurnian.

\section{pH}

Berdasarkan histgram nilai $\mathrm{pH}$ Semi Refined Carrageenan (SRC) dapat dilihat bahwa nilai $\mathrm{pH}$ untuk sampel A yaitu 8,06; sedangkan untuk sampel B yaitu 8,69 .

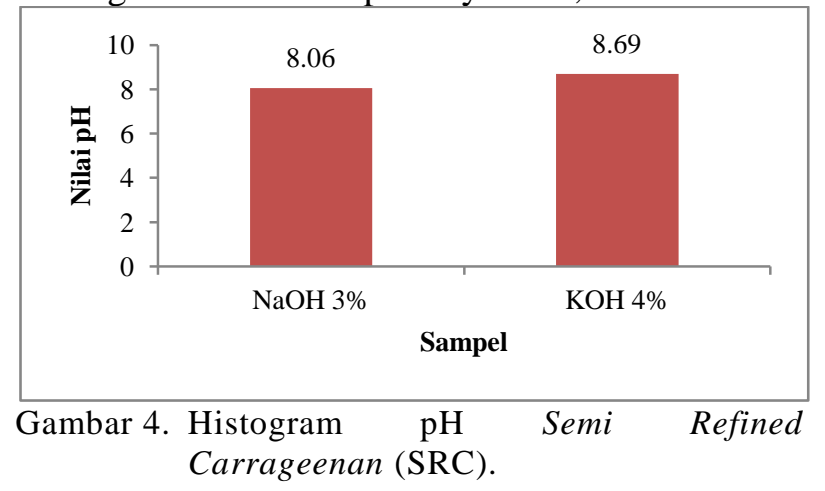

Hal ini membuktikan bahwa konsentrasi $\mathrm{KOH}$ sangat mempengaruhi rendemen yang 
dihasilkan karena semakin tinggi konsentrasi $\mathrm{KOH}$ selama proses alkalisasi berlangsung, menyebabkan pHnya semakin tinggi sehingga kemampuan $\mathrm{KOH}$ dalam mengekstrak semakin besar. Nilai $\mathrm{pH}$ yang didapatkan oleh Erjanan (2017) adalah 8,18 dengan lama pemasakan 3 jam, $\mathrm{KOH} 0,1 \%+\mathrm{KCL} 1 \%$, sedangkan untuk lama pemasakan 3 jam, $\mathrm{KOH} 0,15 \%+\mathrm{KCL}$ $1,15 \%$ yaitu 7,40 . Hal ini membuktikan bahwa konsentrasi dari KCL juga dapat mempengaruhi nilai $\mathrm{pH}$ dimana semakin tinggi konsentrasi $\mathrm{KCL}$, semakin rendah nilai $\mathrm{pH}$. Karaginan sangat stabil pada $\mathrm{pH} 7$ atau lebih tinggi dari 7 , sedangkan pada $\mathrm{pH}$ yang lebih rendah dari 7 maka stabilitas karaginan menurun khususnya dengan adanya peningkatan suhu (Rifansyah, 2016). Jadi pada penelitian ini, mutu karaginan yang dihasilkan tergolong baik karena stabilitas $\mathrm{pH}$ lebih dari 7.

\section{KESIMPULAN DAN SARAN}

\section{Kesimpulan}

Hasil yang diperoleh pada penelitian ini bahwa dengan menggunakan metode uap serta konsentrasi alkali yang rendah didapatkan Semi Refined Carrageenan yang putih dan halus serta hasil Semi Refined Carrageenan yang diperoleh dengan menggunakan larutan basa menghasilkan Semi Refined Carrageenan dengan kualitas yang baik. Dapat dilihat dari hasil pengujian yang diperoleh meliputi: Rendemen, kadar air, kadar abu dan nilai $\mathrm{pH}$.

\section{Saran}

Perlu dilakukan uji lanjut seperti gel streght, viskositas dan derajat putih.

\section{DAFTAR PUSTAKA}

Anwar Fauzi, Djunaedi Ali, Gunawan Widi Santosa., 2013. Pengaruh Konsentrasi KOH yang Berbeda Terhadap Kualitas Alginat Rumput Laut Coklat Sargassum duplicatum J. G. Agardh. Journal Of Marine Research. 2(1):7-14

Bunga, S.M, Montolalu, R.I, Harikedua, Montalalu, L, Watung, H, dan Taher, N. 2013. Karakteristik Sifat Fisika Kimia Karaginan Rumput Laut Kappaphycus alvarezii Pada Berbagai Umur Panen Yang Diambil dari Daerah Perairan Desa Arakan Kabupaten Minahasa Selatan. Universitas Sam Ratulangi. Jurnal Media Teknologi Hasil Perikanan. Vol. 1 No.2

Dalimunthe, H. 2015. Effect of Destillation Temperature ib Quality and Yield of Patchouli Oil of Direct Steam Destillation Type. Jurnal Rekayasa Pangan, Vol; 3

Desiana, E, dan Hendrawati, T. 2015. Pembuatan Karagenan dari Eucheuma cottonii Dengan Ekstraksi
KOH Menggunakan Variabel Waktu Ekstraksi. Fakultas Teknik. Universitas Muhammadiyah Jakarta.

Ega. L., C. G. C. Lopulalan, dan F. Meiyasa. 2016. Artikel Penelitian Kajian Mutu Karaginan Rumput Laut Eucheuma cottonii Berdasarkan Sifat FisikoKimia pada Tingkat Konsentrasi Kalium Hidroksida $(\mathrm{KOH})$ yang Berbeda. Jurnal Aplikasi Teknologi Pangan. 5 (2) : 38-44.

Erjanan, S. Dotulong, V dan Montolalu, R. 2017. Mutu Karagianan dan Kekuatan Gel dari Rumput Laut Merah Kappaphycus alvarezii. Universitas Sam Ratulangi. Jurnal Media Teknologi Hasil Perikanan. Vol. 5 No.2.

Gerung G, Soeroto B, Ngangi E. 2008. Study on the Environment and Trials Cultivation of Kappaphycus and Eucheuma in Nain Island, Indonesia. IFC PENSA - Faculty of Fisheries and Marine Science, Univ. of Sam Ratulangi.

Harun, M., Montolalu, R., Suwetja. 2013. Karakteristik Fisika Kimia Karaginan Rumput Laut Jenis Kappaphycus alvarezii pada umur panen yang berbeda di Perairan Desa Tihengo Kabupaten Gorontalo Utara. Jurnal Media Teknologi Hasil Perikanan. Universitas Sam Ratulangi. Manado

Hidayat, A., 2004. Pengaruh Kelembaban Udara Terhadap Kualitas Rumput Laut Kering Asin Jenis Eucheuma cottonii dan Gracillaria sp Selama Penyimpanan. Departemen Teknologi Hasil Perikanan, Fakultas Perikanan dan Ilmu Kelautan, Institut Pertanian Bogor, Bogor. Kasim, S. R. 2004.

Masthora, S., dan Abdiani I. 2016. Studi kandungan karaginan rumput laut Kappaphycus sp. Pada umur panen yang berbeda. Jurnal harpodon Borneo. Vol: 9 No: 1

Montolalu, R.I., Tashiro, Y., Matsukawa, S., dan Ogawa, H. 2007. Effects of Extraction Parameters on Gel Properties of Carrageenan from Kappaphycusalvarezii (Rhodophyta) Nineteenth International Seaweed Symposium, 71-76

Mudeng, J. Ngangi, L.A. 2014. Culture Pattern of Seaweed Kappaphycus Alvarezii at Nain Island Regency of North Minahasa. Budidaya Perairan. Vol. 2 No. 2: 27-37

Nasruddin, A. N., Asikin, dan I. Kusumaningrum. 2016. Pengaruh Konsentrasi KOH Terhadap Karakteristik Karaginan dari Kappaphycus alvarezii. Jurnal Ilmu Perikanan Tropis. 21 (2) : 55-63.

Poke, A.M., Gerung, G.S., Montolalu, R.I. 2014. Study on Carrageenan content and Growth of Seaweed, Kappaphycus alvarezii infected by white spot disease using different doses of NPK in Banggai Islands. Aquatic Science \& Management. Jurnal Ilmu dan Manajemen Perairan. 31-35

Prasetyowati. Jasmin, C. dan Agustiawan D. 2008. Pembuatan Tepung Karaginan dari Rumput Laut (Eucheuma cottonii) Berdasarkan Perbedaan Metode Pengendapan. Jurnal Teknik Kimia. Vol : 15

Rifansyah, A. 2016. Isolasi Dan Karakterisasi Karaginan Dari Alga Merah Eucheuma cottonii Dengan Metode Pengendapan Garam Alkali. Universitas Bandar Lampung. Skripsi.

Rizal, M., Mappiratu, dan A. R. Razak. 2016. Optimalisasi Produksi Semi Refined Carrageenan 
(SRC) dari Rumput Laut (Eucheuma cottonii). Jurnal Kovalen. 2 (1) : 33-38

Sanger, G., Widjanark, SB., Kusnadi, J., Berhimpon, S. 2013. Antioxidant Activity of Methanol Extract of Sea Weeds Obtained from North Sulawesi. Food Science and Quality Management. Vol. 9

Saputra, R. 2012. Pengaruh Konsentrasi Alkali dan Rasio Rumput Laut-Alkali Terhadap Viskositas dan Kekuatan Gel Semi Refined Carrageenan (SRC) dari Rumput Laut Eucheuma Cottonii. (Skripsi). Universitas Hasanuddin. Makassar. $53 \mathrm{hlm}$.

Tamaheang, T., Makapedua, D., Berhimpon. 2017. Kualitas Rumput Laut Merah (Kappaphycus alvarezii) dengan metode pengeringan sinar matahari dan cabinet dryer serta rendemen semi-refined carrageenan (SRC). Jurnal Media Teknologi Hasil Perikanan. Universitas Sam Ratulangi .Manado.

Togas, C., Berhimpon, S., Montolalu, R., Dien, H., dan Mentang, F. 2018. Physical Charcteristic od Edible Film made from Crrageenan and Beeswax Composites through Nanoelmusion Process. Jurnal Pengolahan Hasil Perikanan Indonesia. 20 (3), 468-477

Winarno, F. G. 2002. Kimia Pangan dan Gizi. Gramedia Pustaka Utama. Jakarta. 